\title{
summary
}

\section{No difference between the single dose efficacy of ibuprofen and diclofenac}

Collins S, Moore A, McQuay HJ, Wiffen PJ. Oral ibuprofen and diclofenac in post-operative pain: a quantitative systematic review. Eur J Pain 1998; 2:285-291

Objective To compare the relative efficacy of ibuprofen and diclofenac in post-operative pain.

Data sources A search of the following databases, Medline 19661996, Embase 1980-1997, Cochrane Library August, 1996, Oxford Pain relief database 1950-1994, together with reference lists and textbooks, using a detailed search strategy.

Study selection Only full journal publication of double-blind studies with randomly allocated adult patients receiving postoperative oral administration for treatment of moderate to severe pain baseline pain (equates to $>30 \mathrm{~mm}$ on a visual analogue scale, VAS), using acceptable pain measures.

Results Thirty-four reports of 35 trials met the criteria, (25 dental) for ibuprofen versus placebo, six for diclofenac versus placebo (five dental) and two direct comparisons between diclofenac and ibuprofen both for dental pain.

Conclusion No difference was seen in efficacy of the single dose of ibuprofen compared with that of diclofenac; choosing between the two is a matter of safety and cost.

\begin{tabular}{|c|c|c|c|c|c|}
\hline \multirow[t]{2}{*}{$\begin{array}{l}\text { Ibuprofen } \\
\text { dose (mg) }\end{array}$} & \multirow[t]{2}{*}{$\begin{array}{l}\text { Number } \\
\text { of trials }\end{array}$} & \multicolumn{2}{|c|}{$\begin{array}{l}\text { Patients with at least } 50 \% \\
\text { pain relief }\end{array}$} & \multirow[t]{2}{*}{$\begin{array}{l}\text { Risk ratio } \\
(95 \% \mathrm{Cl})\end{array}$} & \multirow[t]{2}{*}{$\begin{array}{c}\text { NNT } \\
(95 \% \mathrm{Cl})\end{array}$} \\
\hline & & ibuprofen & placebo & & \\
\hline 100 & 2 & $16 / 88$ & 0/98 & $72(16-318)$ & $5.6(3.8-9.9)$ \\
\hline 400 & 30 & $858 / 1606$ & 214/1292 & $3.3(2.5-4.3)$ & $2.7(2.5-3.0)$ \\
\hline 800 & 1 & $39 / 39$ & $14 / 37$ & $2.6(1.8-4.0)$ & $1.6(1.3-2.2)$ \\
\hline \multirow[t]{2}{*}{$\begin{array}{l}\text { Diclofenac } \\
\text { dose (mg) }\end{array}$} & \multirow[t]{2}{*}{$\begin{array}{l}\text { Number } \\
\text { of trials }\end{array}$} & $\begin{array}{l}\text { Patients with } \\
\text { pain }\end{array}$ & $\begin{array}{l}\text { at least 50\% } \\
\text { elief }\end{array}$ & $\begin{array}{l}\text { Risk ratio } \\
(95 \% \mathrm{Cl})\end{array}$ & $\begin{array}{c}\text { NNT } \\
(95 \% \mathrm{Cl})\end{array}$ \\
\hline & & diclofenac & placebo & & \\
\hline 25 & 1 & $23 / 50$ & $4 / 50$ & $5.8(2.1-15.4)$ & $2.6(1.9-4.5)$ \\
\hline 50 & 6 & $2.3 / 324$ & $57 / 312$ & $4.3(2.4-7.8)$ & $2.3(2.0-2.7)$ \\
\hline 100 & 3 & $100 / 154$ & $13 / 154$ & $7.2(5.5-9.4)$ & $1.8(1.5-2.1)$ \\
\hline
\end{tabular}

Supported by grants from NHSR\&D Health Technology Evaluation Programme (\#93/31/4 and \#94/11/4), European Union Biomed 2 BMH4 CT95 0172and Pain Research funds.

Address for reprints: Dr A Moore, Pain Research and Nuffield Department of Anaesthetics, University of Oxford, Oxford Radcliffe NHS Trust, The Churchill, Headington, Oxford OX3 7LJ, UK.

\section{Commentary}

This systematic analysis of the literature evaluates 34 published drug trials of acute pain relief following a single dose of either ibuprofen or diclofenac. Ibuprofen, which entered the analgesic market over 20 years ago, can be considered the 'gold standard' for the newer non-steroidal anti-inflammatory drugs (NSAIDs). There is little evidence to indicate that any of the newer NSAID analgesics, when compared with ibuprofen 400-600 mg, have superior analgesic efficacy. This review, while stratifying for analgesic dose, comes to the same conclusion: ibuprofen and diclofenac have essentially equal analgesic efficacy.

The justification for prescribing a particular NSAID analgesic is most frequently based on lower incidence of side effects or certain pharmacokinetic advantages such as rapid onset, longer duration, or fewer drug interactions. Without a clear therapeutic advantage, a practitioner or a third party cannot justify significant differences in prescription costs.

The authors report that the British prescription rate for diclofenac was equivalent to ibuprofen (6 versus 5.5 million/year in 1996). It is notable that diclofenac (Voltaren) is not a commonly prescribed analgesic in the USA. In the 1999 accounting of the 'Top 200' prescriptions, diclofenac is not listed ${ }^{1}$. The NSAID analgesic prescription rate has decreased in part due to the availability of the over-the counter (OTC) analgesics naproxen, ibuprofen and ketoprofen. Most prescription use of the NSAIDs is not for acute analgesia, but for anti-inflammatory indications such as arthritis. Acetaminophen with hydrocodone, celecoxib, acetaminophen with codeine, propoxyphene with acetaminophen, tramadol, ibuprofen, nabumetone, naproxen, rofecoxib and acetaminophen with oxycodone are the most frequently prescribed analgesics (by rank) reported in 1999.

1. RxList - The Top 200, http:// www.rxlist.com/top200.htm (6/15/200)

\section{Paul A Moore School of Dental Medicine, University of Pittsburgh, USA}

